Commentary

\title{
Commentary on Fanaroff et al., Levels of Evidence Supporting American College of Cardiology/American Heart Association and European Society of Cardiology Guidelines, 2008-2018. JAMA. 2019;321(11):1069-80
}

\author{
Giuseppe Mancia \\ University of Milano-Bicocca, Milan 20126, Italy; \\ Email: giuseppe.mancia@unimib.it.
}

I agree with the conclusion of Fanaroff et al. [1] that only a small number of the recommendations of the American College of Cardiology/American Heart Association (ACC/AHA) or European Society of Cardiology (ESC) guidelines is based on the strongest class and level of evidence, i.e., the one that the authors term "LOE A", and that is based on multiple trials or a single large randomized trial. Indeed, as I mentioned in a chapter on guidelines published in a recent book on hypertension [2], this is entirely true also for the guidelines on hypertension jointly issued in 2013 by the European Society of Hypertension (ESH) and the ESC [3]. In these guidelines the recommendations which were classified as being $1 \mathrm{~A}$ for class and level of evidence, and thus based on randomized trials, were only $27 \%$ of all recommendations. This has been the case also for the recommendations classified as 1A (30\%) in the 2018 ESC/ESH hypertension guidelines [4].

The problem is, however, what significance we should give to this low rate of randomized trial-based evidence. In the interpretation of Fanaroff et al. [1] the significance seems to me that guidelines have a limited scientific basis and that thus most of their recommendations can be disputable. This has an element of truth because in many cardiovascular areas, including hypertension, evidence is weak, incomplete or even

G Open Access

Received: 12 April 2019 Accepted: 09 May 2019 Published: 13 May 2019

Copyright $@ 2019$ by the author(s). Licensee Hapres, London, United Kingdom. This is an open access article distributed under the terms and conditions of Creative Commons Attribution 4.0 International License. absent, inevitably amplifying data interpretation and expert opinions at the expense of objectively-derived recommendations. Some additional considerations, however, may be appropriate. One is that randomized trials are not a feasible approach to cardiovascular areas which are an important component of guidelines, such as epidemiology, diagnosis and patients' follow-up. For hypertension this includes the recommendations on how to measure office blood pressure, if and when to use home and/or ambulatory blood pressure monitoring, how to quantify cardiovascular risk and whether and which organ damage to search for, just to mention few examples. Theoretically, also diagnostic aspects might benefit from a randomized study design to determine, in patients with similar clinical phenotypes, which is the outcome when screening includes or does not 
include organ damage, blood pressure is measured one or more time in an attended or unattended fashion, cardiovascular risk is quantified by an expanded or restricted number of risk factors, or follow-up makes use of one or more visits per year. This, however, would represent a very complex and for many reasons unrealistic approach, which is why information on virtually all diagnostic aspects of hypertension originate from observational studies. The domain of randomized trials is thus restricted to treatment, again, however, with some important limitations that are perhaps not sufficiently emphasized. An example is that, for logistical and economic reasons, randomized trials on the treatment of hypertension (but also of dyslipidemia and diabetes) have a duration almost never longer than 5-6 years, which means that the guidelines recommendations for the treatment of patients over the lifetime (30-40 years in many patients) have to be based, once more, on observational studies, often made available by a non-randomized prolongation of trials. Another example is that randomized trials are far from being the ideal approach to study therapeutic inertia and adherence to the prescribed treatment regimen because in trials both doctors and patients are highly motivated, leading to much lower inertia and higher adherence levels than in clinical practice. These crucial aspects of treatment, to which guidelines' attention has grown substantially in the last few years, can be much more conveniently assessed by studies performed in a real life setting (when doctors and patients are not aware of being under observation), which thus provide the best evidence for these guidelines recommendations.

The time might have come not to consider clinical trials as the unconditional model for all clinical research, the bible to which refer to for any medical evidence, but to determine which research approach is more suitable for data collection under different circumstances or for different clinical problems, and grade the available evidence accordingly. This means to upgrade the information obtained by observational and real life research and acknowledge that this may represent the best research approach for issues with no less importance for treatment than establishing, by randomized trials, that one drug is better than another over a fraction of most patients' treatment duration.

\section{CONFLICTS OF INTEREST}

The author declares that there is no conflict of interest.

\section{REFERENCES}

1. Fanaroff AC, Califf RM, Windecker S, Smith SC, Lopes RD. Levels of evidence supporting American College of Cardiology/Americah Heart Association and European Society of Cardiology Guidelines, 2008-2018. JAMA. 2019;321:1069-80.

2. Townsend RR, Mancia G. Updated American Heart Association/American College of Cardiology; European Society of Hypertension/International Society of Hypertension Guidelines. In: Bakris GL, Sorrentino MJ, editors. 
Hypertension: A Companion to Braunwald's Heart Disease. 3rd ed. Philadelphia (PA, US): Elsevier; 2017. p. 459-67.

3. Mancia G, Fagard R, Narkiewicz K, Redon J, Zanchetti A, Böhm M, et al. The Task Force for the management of arterial hypertension of the European Society of Hypertension (ESH) and of the European Society of Cardiology (ESC). $2013 \mathrm{ESH} / \mathrm{ESC}$ Guidelines for the management of arterial hypertension. J Hypertens. 2013;31:1281-357.

4. Williams B, Mancia G, Spiering W, Agabiti Rosei E, Azizi M, Burnier M, et al. The Task Force for the management of arterial hypertension of the European Society of Cardiology (ESC) and the European Society of Hypertension (ESH). 2018 ESC/ESH Guidelines for the Management of Arterial Hypertension. J Hypertens. 2018;36:1953-2041.

How to cite this article:

Mancia G. Commentary on Fanaroff et al., Levels of Evidence Supporting American College of Cardiology/American Heart Association and European Society of Cardiology Guidelines, 2008-2018. JAMA. 2019;321(11):1069-80. Med One.

2019;4:e190008. https://doi.org/10.20900/mo.20190008 